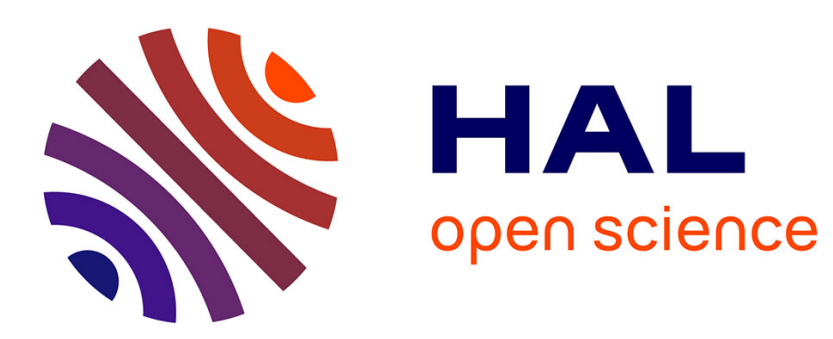

\title{
Enantioselective organocatalytic activation of vinylidene--quinone methides (VQMs)
}

Jean Rodriguez, Damien Bonne

\section{To cite this version:}

Jean Rodriguez, Damien Bonne. Enantioselective organocatalytic activation of vinylidene-quinone methides (VQMs). Chemical Communications, 2019, 55 (75), pp.11168-11170. 10.1039/c9cc05097c . hal-02354840

\author{
HAL Id: hal-02354840 \\ https://hal.science/hal-02354840
}

Submitted on 7 Nov 2019

HAL is a multi-disciplinary open access archive for the deposit and dissemination of scientific research documents, whether they are published or not. The documents may come from teaching and research institutions in France or abroad, or from public or private research centers.
L'archive ouverte pluridisciplinaire HAL, est destinée au dépôt et à la diffusion de documents scientifiques de niveau recherche, publiés ou non, émanant des établissements d'enseignement et de recherche français ou étrangers, des laboratoires publics ou privés. 


\title{
Enantioselective organocatalytic activation of vinylidene-quinone methides (VQMs)
}

\author{
Jean Rodriguez (iD) * and Damien Bonne (iD)* \\ Vinylidene-quinone methides (VQMs) are highly electrophilic chiral reagents that can be generated \\ in situ from 2-(phenylethynyl)phenols. They were characterized for the first time in 2012 but their \\ enantioselective organocatalytic activation was addressed only very recently. Their specific reactivity has \\ revealed innovative strategies notably for the control of axial chirality.
}

Vinylidene-quinone methides (VQMs) were synthesized and identified for the first time in 2012 by Freccero via excitedstate intramolecular proton transfer (ESIPT) by irradiation of ortho-alkynylphenols. ${ }^{1,2}$ These intriguing highly electrophilic intermediates are variants of well-known ortho-quinone methides (o-QMs) widely used in enantioselective transformations. ${ }^{3}$ A critical feature of VQMs 2 is their intrinsic axial chirality that can be controlled during their generation from 2-alkynylnaphthols 1 with a chiral non-racemic organocatalyst (Scheme 1). ${ }^{4}$ Once generated, VQMs can be involved in stereoselective cycloadditions or nucleophilic additions with transfer of chirality. This allows access to original centrally chiral enantioenriched polycyclic pyrans 3 or to axially chiral naphthols 4 .

The first example of enantioselective activation of a VQM was described by the group of Irie in 2013 (Scheme 2). ${ }^{5}$ The use of cinchonidine as the organocatalyst directly transformed symmetric

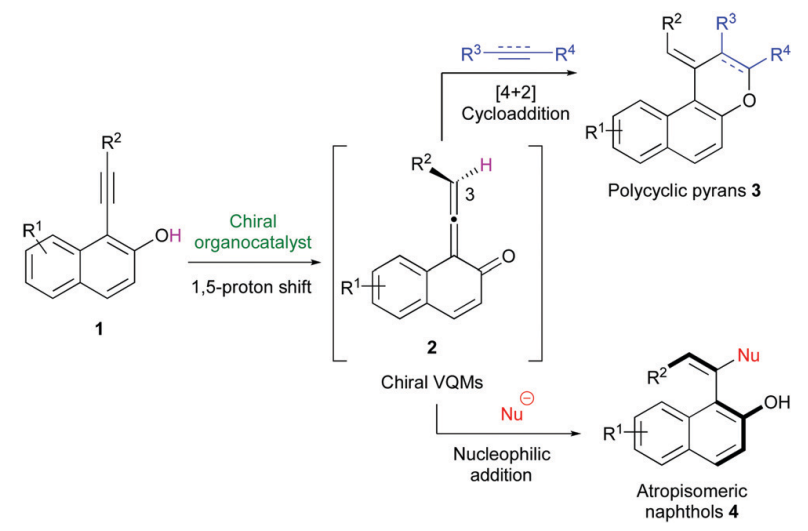

Scheme 1 Exploiting the reactivity of chiral VQMs.

Aix Marseille Université, CNRS, Centrale Marseille, iSm2, Marseille, France. E-mail: damien.bonne@univ-amu.fr, jean.rodriguez@univ-amu.fr
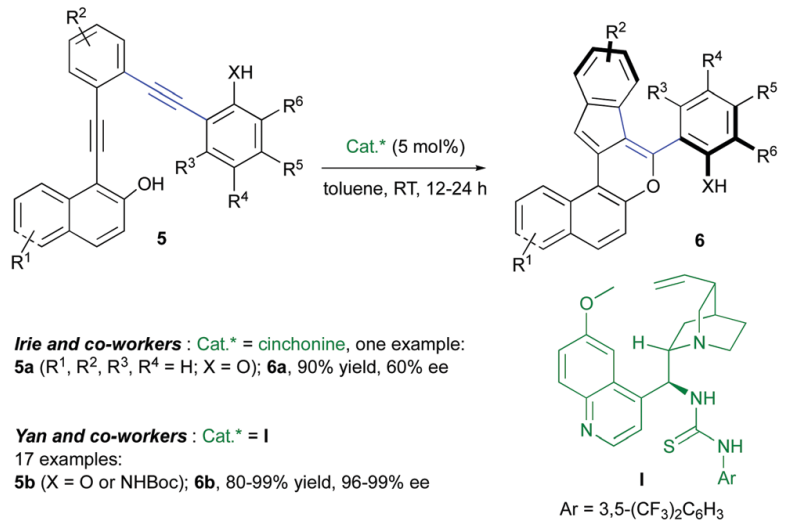

Scheme 2 Enantioselective synthesis of 2-aryl naphthopyran atropisomers.

bis-2-alkynylnaphthol 5a to axially chiral pyran $\mathbf{6 a}$ in good yield and moderate enantioselectivity through an intramolecular inverseelectron demand hetero-Diels-Alder reaction. This original strategy has been exemplified and developed last year by the group of Yan using a quinine-derived thiourea I for the organocatalytic activation. ${ }^{6}$ Under these optimized conditions, this unique transformation proceeds highly chemo- and enantioselectively even with challenging non-symmetric bis-alkynylnaphthols $\mathbf{5 b}$.

Recently, DFT calculations showed that the axial chirality of the VQM intermediate is generated during the protonation step (Scheme 3). ${ }^{7}$ First, the thiourea moiety of the catalyst acts as a Brønsted acid to activate the functionalized naphthol 5, which is deprotonated by the tertiary amine moiety of the catalyst $\mathbf{I}$ to form the intermediate 7. Afterward, the alkyne is enantioselectively protonated by the ammonium salt of the catalyst to give the chiral VQM intermediate 8, via the transition state 9. Then, a transfer of chirality operates during the key intramolecular [4+2]-hetero-DielsAlder cycloaddition leading to 6 . 


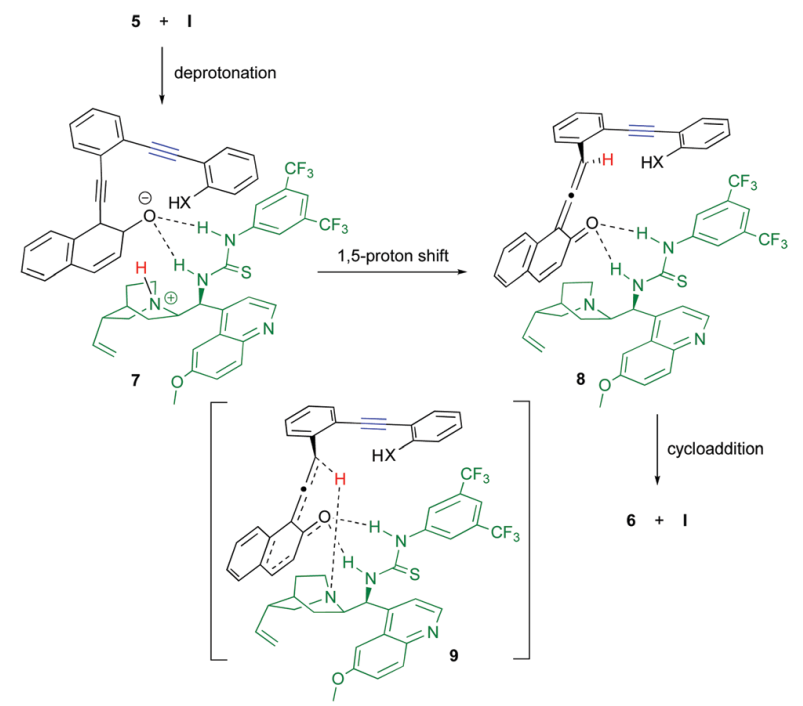

Scheme 3 Origin of stereocontrol in the formation of chiral VQM intermediates.

Contemporaneously, the same two groups disclosed the peculiar reactivity of mono-2-alkynylnaphthols 10 bearing a pendent benzofuran ring as the dienophile. The resulting $[4+2]$ cycloaddition provided centrally chiral oxygenated polyheterocycles 11. While moderate enantioselectivities were found with cinchonine and cinchonidine, ${ }^{8 a}$ the bifunctional thiourea organocatalyst I gave excellent enantio- and diastereoselectivities (Scheme 4). ${ }^{8 b}$ Moreover, deuterium-labelling experiments clearly established that the source of the hydrogen atom at $\mathrm{C} 3$ of $\mathbf{2}$ (Scheme 1) originated from the hydroxyl group of $\mathbf{1}$, via an organocatalyzed enantioselective 1,5-proton shift.

In complement to the previous work involving a benzofuran ring as the dienophile, Yan and co-workers showed that 2-alkynylnaphthols $\mathbf{1 2}$ bearing a bis-indole moiety could undergo intramolecular dearomatizing [4+2]-cycloaddition with VQMs to form fused indolines 13 with excellent stereoselectivities (Scheme 5). ${ }^{9}$

In contrast to these cycloadditions, Deng and Yan described the first atroposelective nucleophilic addition of sodium arylsulfinates 14 to VQMs, generated by 1,5-proton shift from simple 2-alkynylnaphthols $\mathbf{1}$ with organocatalyst I (Scheme 6). ${ }^{10}$ Axially chiral sulfone-containing styrenes $\mathbf{1 5}$ were obtained with excellent enantioselectivities and almost complete $E$ selectivity. L-Proline used as co-catalyst, whose configuration does not play a

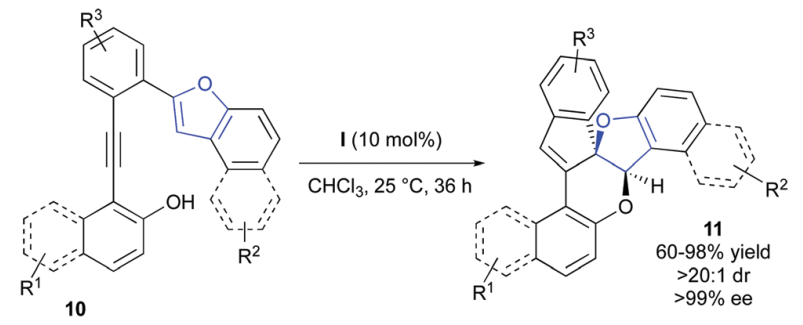

Scheme 4 Enantioselective construction of [5-6-5] tricyclic heterocycles.

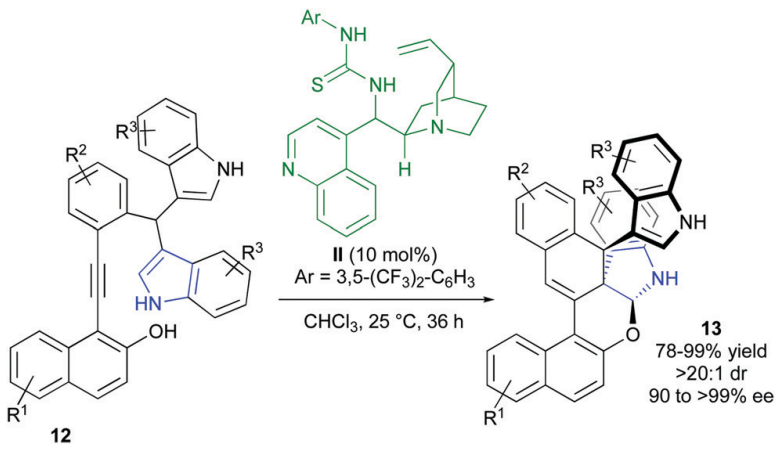

Scheme 5 Desymmetrizing dearomatization of bis-indoles.

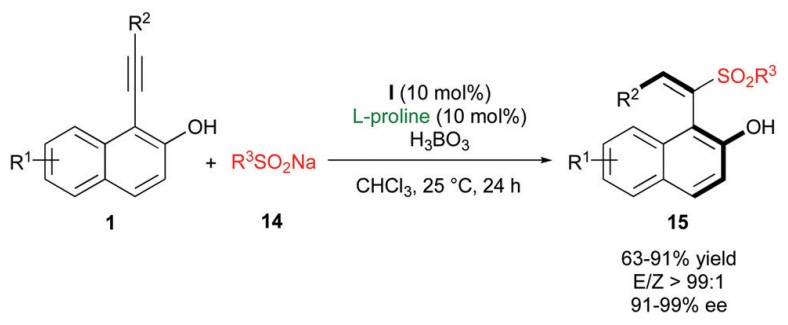

Scheme 6 Atroposelective synthesis of styrenes.

role in the enantiodiscrimination, allowed the in situ generation of an activated ammonium sulfinate salt with increased solubility and reactivity. A bidirectional version from 1,4-dialkynylnaphthalene2,3-diols allowed for the efficient synthesis of the corresponding double axis chiral diols. ${ }^{11}$

The same authors reached an increased level of complexity by the three-component enantioselective synthesis of multiaxis systems 18a (Scheme 7a). ${ }^{12}$ The use of squaramide organocatalyst III in combination with $N$-iodosuccinimide (NIS) as an electrophile allows the transient generation of highly reactive iodo-functionalized tetrasubstituted chiral VQMs 19. Sulfinic acid $\mathbf{1 7}$ trapping afforded the desired vicinal diaxial styrenes $\mathbf{1 8 a}$ in good yields and excellent diastereo- and enantioselectivities. Starting from a racemic axially chiral substrate $\mathbf{1 6}$ (Scheme $7 \mathrm{~b}$ ), three stereogenic axes could be controlled in $\mathbf{1 8 b}$ through an additional kinetic resolution.

Sodium sulfinate can be replaced by $5 \mathrm{H}$-oxazol-4-ones allowing the enantioselective synthesis of intriguing molecules bearing $E, Z$ configurations, stereogenic carbon atoms and axially chiral styrenes. ${ }^{13}$

In a very complementary manner to the work detailed in Scheme 4, the group of Irie showed that VQMs from 20, bearing a pendent indole moiety, evolved by hydroarylation at C3 rather than by a [4+2] cycloaddition like bis-indoles $12 .{ }^{14}$ Hence, VQMs undergo atroposelective intramolecular Michael-type additions leading to axially chiral benzocarbazoles 21 (Scheme 8).

A more recent breakthrough in the emerging chemistry of VQMs is due to Tan and co-workers using chiral phosphoric acid (CPA) activation. This allows for the first time, nucleophilic addition of simple phenols 23 to either ortho-alkynyl-naphthols or -naphthylamines $\mathbf{2 2}$ affording the atropisomeric styrenes $\mathbf{2 4}$ 
<smiles>[R]c1ccc2ccccc2c1C#Cc1c(O)ccc2ccccc12</smiles>

16<smiles>CC(C)C=C1C(=O)C=Cc2ccccc21</smiles>

17<smiles>C=CC1CC2CCN1C(c1ccnc3ccc(O)cc13)C2Nc1c(N[Al])c(=O)c1=O</smiles>

17

b)<smiles>[R1]c1ccccc1-c1ccc2ccccc2c1C#Cc1c(O)ccc2c1C=C[R1]C=C2</smiles>

$( \pm)-16$

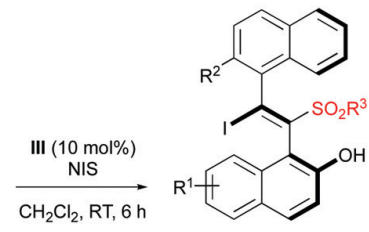

$18 \mathrm{a}$ $2-93 \%$
$E / Z>99: 1$ $>20: 1 \mathrm{dr}$ $90-98 \%$ ee
Scheme 7 Enantioselective synthesis of vicinal diaxial styrenes.
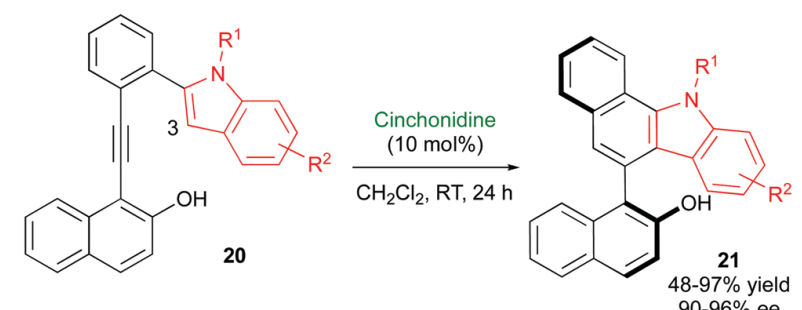

Scheme 8 Enantioselective synthesis of benzocarbazole atropisomers.

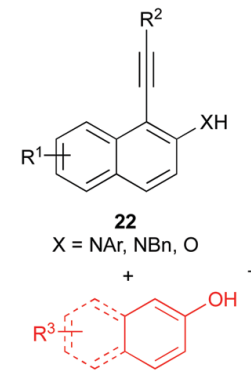

23

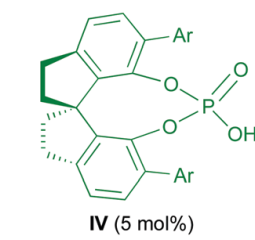

$\mathrm{CH}_{2} \mathrm{Cl}_{2}, 10^{\circ} \mathrm{C}, 48 \mathrm{~h}$

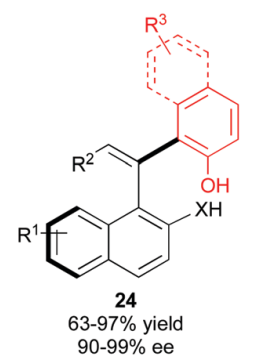

$90-99 \%$ ee
Scheme 9 Enantioselective synthesis of axially chiral EBINOLs. in good yields and excellent enantiocontrol (Scheme 9) ${ }^{15}$ Inspired by the well-known BINOL-type ligands used in enantioselective catalysis, these new axially chiral styrenes were named EBINOLs. These molecules were then derivatized into chiral phosphoric acids and chiral phosphoramidites, which were used with success as original catalysts in a series of enantioselective reactions, such as Friedel-Crafts, hydrogenation or Michael addition.

In conclusion, the use of chiral VQMs in enantioselective transformations is an emerging area of research and several very recent reports have shown their high potential in synthetic chemistry, notably in the control of axial chirality. This opens new possibilities and will have a deep impact on future developments in the synthesis of original atropisomeric compounds.

\section{Conflicts of interest}

There are no conflicts to declare.

\section{Acknowledgements}

Financial support from the Centre National de la Recherche Scientifique (CNRS), Aix-Marseille Université, and Centrale Marseille is gratefully acknowledged.

\section{Notes and references}

1 F. Doria, C. Percivalle and M. Freccero, J. Org. Chem., 2012, 77, 3615-3619. 2 For pioneer, non-stereoselective synthetic transformations involving VQM intermediate, without direct experimental evidence, see: (a) M. Chakraborty, D. B. McConville, T. Saito and H. Meng, Tetrahedron Lett., 1998, 39, 8237-8240; (b) E. Vedejs and P. L. Steck, Angew. Chem., Int. Ed., 1999, 38, 2788-2791.

3 For a review, see: Z. Wang and J. Sun, Synthesis, 2015, 3629-3644.

4 S. Arae, M. Furusawa, S. Beppu, K. Igawa, K. Tomooka and R. Irie, Chimia, 2018, 72, 892-898.

5 M. Furusawa, K. Arita, T. Imahori, K. Igawa, K. Tomooka and R. Irie, Tetrahedron Lett., 2013, 54, 7107-7110.

6 Y. Liu, X. Wu, S. Li, L. Xue, C. Shan, Z. Zhao and H. Yan, Angew. Chem., Int. Ed., 2018, 57, 6491-6495.

7 C. Shan, T. Zhang, Q. Xiong, H. Yan, R. Bai and Y. Lan, Chem. - Asian J., 2019, 14, 2731-2736.

8 (a) S. Beppu, S. Arae, M. Furusawa, K. Arita, H. Fujimoto, M. Sumimoto, T. Imahori, K. Igawa, K. Tomooka and R. Irie, Eur. J. Org. Chem., 2017, 6914-6918; (b) X. Wu, L. Xue, D. Li, S. Jia, J. Ao, J. Deng and H. Yan, Angew. Chem., Int. Ed., 2017, 56, 13722-13726.

9 L. Peng, D. Xu, X. Yang, J. Tnag, X. Feng, S.-L. Zhang and H. Yan, Angew. Chem., Int. Ed., 2019, 58, 216-220.

10 S. Jia, Z. Chen, N. Zhang, Y. Tan, Y. Liu, J. Deng and H. Yan, J. Am. Chem. Soc., 2018, 140, 7056-7060.

11 S. Li, D. Xu, F. Hu, D. Li, W. Qin and H. Yan, Org. Lett., 2018, 20, 7665-7669.

12 Y. Tan, S. Jia, F. Hu, Y. Liu, L. Peng, D. Li and H. Yan, J. Am. Chem. Soc., 2018, 140, 16893-16898.

13 A. Huang, L. Zhang, D. Li, Y. Liu, H. Yan and W. Li, Org. Lett., 2019, 21, 95-99.

14 S. Arae, S. Beppu, T. Kawatsu, K. Igawa, K. Tomooka and R. Irie, Org. Lett., 2018, 20, 4796-4800.

15 Y.-B. Wang, P. Yu, Z.-P. Zhou, J. Zhang, J. Wang, S.-H. Luo, Q.-S. Gu, K. N. Houk and B. Tan, Nat. Catal., 2019, 2, 504-513. 